\title{
AVALIAÇÃO DA INFLUÊNCIA DO APORTE TÉRMICO NA ZTA DE JUNTAS SOLDADAS DE AÇO INOX DUPLEX EM COMPARAÇÃO ENTRE OS PROCESSOS DE SOLDAGEM TIG E FCAW *
}

Marcela Alves Silva Reginaldo Pinto Barbosa² Erriston Campos Amara/ ${ }^{3}$

\section{Resumo}

Os aços inoxidáveis duplex - AID são ligas de Fe-Cr-Ni com no mínimo de 10,5\% de $\mathrm{Cr}$, promovendo uma película superficial aderente de $\mathrm{Cr}_{2} \mathrm{O}_{3}$, com proteção a corrosão e proporção microestrutural de austenita e ferrita próximas a $50 \%$, potencializando as propriedades mecânicas e resistência à corrosão.Possuem boa soldabilidade, porém pode provocar um desbalanceamento microestrutural e a precipitação de fases deletérias, acarretando o declínio das propriedades, principalmente na zona afetada termicamente - ZTA. Desta forma o presente trabalho tem como objetivoavaliar à influência da energia de soldagem sobre a ZTA da junta soldada de AID, comparando soldas realizadas pelo processo TIG e FCAW levando em consideração 0 balanceamento das fases ferrita e austenita. Para tanto, foram realizadas soldas com parâmetros comumente utilizados nas indústrias em geral. As amostras apresentadas foram soldadas de acordo com o padrão da Thermon Indústria Mecânica, uma das colaboradoras deste projeto. Conclui-se que a comparação entre os dois processos distintos resultou em fatos já esperados, embasado na revisão bibliográfica, onde o corpo de prova soldado pelo processo TIG apresentou menor região propensa a fragilizações, menor ZTA. As frações de austenita e ferrita em cada corpo de prova foram similares nesta região.

Palavras-chave:Soldabilidade; Microestrutura; Aço inoxidável Duplex.

\section{INFLUENCE OF EVALUATION OF HEAT INPUT OF ZTA WELDED JOINTS OF STAINLESS STEEL DUPLEX IN COMPARISON BETWEEN TIG WELDING PROCESSES AND FCAW}

\section{Abstract}

Duplex stainless steels - DSS are $\mathrm{Fe}-\mathrm{Cr}-\mathrm{Ni}$ with at least $10.5 \% \mathrm{Cr}$, promoting an adherent surface film of $\mathrm{Cr} 2 \mathrm{O} 3$ with corrosion protection and microstructural proportion of austenite and ferrite close to $50 \%$, increasing the mechanical properties and corrosion resistance. Good weldability, but can cause an imbalance microstructural and precipitation of deleterious phases, leading to the decline of the properties, especially in the heat affected zone - HAZ. Thus, the present study aims to evaluate the influence of welding energy on the HAZ of the welded joint DSS comparing welds performed by TIG and FCAW process taking into account the balance of ferrite and austenite phases. Therefore, parameters welds were performed commonly used in general industries. The samples submitted were performed according to the standard of Thermon Mechanical Industry, one of the collaborators of this project. It is concluded that the comparison between the two processes resulted in facts already expected, based on the literature review, where the specimen welded by TIG process showed less prone region embrittlement, lower ZTA. The fractions of austenite and ferrite in each specimen were similar in this region.

Keywords: Weldability; Microstructure; Duplex stainless steel.

1 Graduanda em Engenharia Metalúrgica, Centro Universitário do Leste de Minas Gerais - Unileste, Coronel Fabriciano, Minas Gerais, Brasil.

2 Eng. Mecânico, M.Sc., Professor/Pesquisador de Inox, Unileste; Aperam South America, Cel. Fabriciano, Timóteo, MG, Brasil.

3 Engenheiro de Materiais, M.Sc., Professor, CEFET Timóteo, Minas Gerais, Brasil. 


\section{INTRODUÇÃO}

Aços Inoxidáveis Duplex - AID são materiais que aliam alta resistência mecânica com elevada resistência às corrosões por pites, permitidas através sua fina microestrutura bifásica composta por $50 \%$ de austenita e $50 \%$ de ferritae ligas $(\mathrm{Cr}$, Mo e $N)$. Possuem uma película superficial aderente $\left(\mathrm{Cr}_{2} \mathrm{O}_{3}\right)$, chamada de película ou filme passivo, que reduz a corrente de corrosão a níveis insignificantes, protegendo-os de ações de agentes corrosivos [1][2].

Constantemente esses materiais são submetidos a processos de soldagens, os quais envolvem grandes alterações térmicas e o desempenho da junta soldada está relacionado com as transformações ocorridas no material durante as transformações de sua microestrutura, o que pode acarretar em um desbalanceamento na proporção de ferrita e austenita, ou a precipitação de fases intermetálicas [...][3].

A tenacidade ao impacto do AID soldado é deteriorada pelo aumento da fração volumétrica de ferrita delta na zona termicamente afetada (ZTA), por conta da alta temperatura de pico e da alta taxa de resfriamento do ciclo térmico de soldagem. $O$ nitrogênio reforça a microestrutura através do mecanismo de endurecimento por solução sólida intersticial, além de estabilizar a austenita a altas temperaturas[4][5].

Uma energia de soldagem elevada leva um tempo maior para o resfriamento, favorecendo a precipitação de austenita e o equilíbrio microestrutural desejado. Por outro lado, uma baixa energia de soldagem, resulta na diminuição no tempo de resfriamento, retardando a precipitação de austenita e favorecendo o desequilíbrio das fases na microestrutura [2].

Quanto à fonte de energia, quanto mais concentrada for, menor será a extensão da região aquecida e, consequentemente, menor serão as mudanças nas propriedades da junta. A concentração da fonte de energia é medida pela potência específica $\left(\mathrm{W} / \mathrm{m}^{2}\right)[6]$.

Os dois processos de soldagem utilizados foram o TIG e o FCAW. O processo de soldagem TIG ou GasTungstenArcWelding (GTAW) é um processo a arco elétrico, com o arco entre um eletrodo não consumível de tungstênio e a poça de soldagem, onde a poça de soldagem, o eletrodo e parte do cordão são protegidos através do gás de proteção soprado pelo bocal da tocha. No processo, pode-se utilizarmetal de adiçãoou não (solda autógena). É mais usado devido a sua versatilidade, alta qualidade, aparência estética do acabamento da solda e boa capacidade de soldar em baixa corrente.

A soldagem a arco elétrico com arames tubulares ou FluxCoredArcWelding(FCAW) utiliza o arco elétrico estabelecido entre a ponta do arame e a peça de trabalho. A proteção da poça de fusão e do arco elétrico pode ser feita pelo fluxo contido no interior do arame (no caso de arames tubulares autoprotegidos) ou por uma fonte gasosa externa. Esta proteção gasosa é realizada na maioria das vezes utilizando $100 \% \mathrm{CO}_{2}$ como gás de proteção e em alguns casos utilizando misturas $75 \% \mathrm{Ar} / 25 \% \mathrm{CO}_{2}[7]$.

Este trabalho apresenta um estudo da influência de energia de soldagem sobre a região da ZTA na junta soldada de aço inoxidável duplex, comparando assoldas realizadas pelo processo TIG e FCAW, levando em consideração o balanceamento das fases ferrita e austenita, a fim de avaliar claramente os efeitos causados pela energia de soldagem em materiais soldados pelos dois processos distintos. 


\section{MATERIAIS E MÉTODOS}

O metal base de AID, UNS 32205, inicialmente em forma de placas com dimensões de $300 \times 100 \times 4 \mathrm{~mm}$, foi repartido em quatro partes de dimensões $75 \times 100 \times 4 \mathrm{~mm}$. A Tabela 1 informa a composição química do metal de base em percentual de massa.

\begin{tabular}{cc} 
Tabela 1.Composição química do metal de base \\
\hline Elemento & \% em massa \\
\hline C & 0,015 \\
Mn & 1,835 \\
Si & 0,323 \\
Cr & 22,75 \\
Ni & 4,46 \\
Mo & 3,01 \\
\hline
\end{tabular}

Foram utilizados como consumíveis no processo TIG, o gás de proteção argônio puro e como metal de adição a vareta ER 308L, regido pela norma AWS/ASME SFA 5.9 , de composição química, conforme mostrado na Tabela 2.

Para o processo de soldagem FCAW, foi utilizado o gás de proteção $\mathrm{CO}_{2}$ e como metal de adição arame tubular E309 LT, regido pela norma ASME/ SFA AWS A5.22 de composição química, conforme mostrado na Tabela 2 , onde a percentagem de elementos é dada em massa.

Tabela 2. Especificações consumíveis de soldagem

\begin{tabular}{ccc}
\hline Elemento & TIG & FCAW \\
& ER 308L & E 309 LT \\
\hline $\mathbf{C}$ & $<0,030$ & 0,029 \\
$\mathbf{S i}$ & 0,50 & 0,805 \\
$\mathbf{M n}$ & 1,80 & 1,093 \\
$\mathbf{C r}$ & 20,30 & 22,70 \\
$\mathbf{N i}$ & 10,00 & 12,66 \\
$\mathbf{M o}$ & $<0,30$ & 0,080 \\
\hline
\end{tabular}

As soldagens foram realizadas em chapas na posição plana, com a completa união das chapas, utilizando-se o chanfro em X. Depois de soldados, eliminaram-se as pontas iniciais e finais das amostras. Os parâmetros empregados durante a soldagem das chapas são mostrados na Tabela 3.

Tabela 3.Parâmetros dos processos de soldagem

\begin{tabular}{ccc} 
& Amostra 1 (FCAW) & Amostra 2 (TIG) \\
\hline Corrente & $126 \mathrm{~A}$ & $100 \mathrm{~A}$ \\
Tensão & $25 \mathrm{~V}$ & $18 \mathrm{~V}$ \\
Velocidade & $4,66 \mathrm{~mm} / \mathrm{s}$ & $1,66 \mathrm{~mm} / \mathrm{s}$ \\
Pressão do gás & $17 \mathrm{~kg}$ & $12 \mathrm{Kg}$ \\
Eficiência do processo & $90 \%$ & $80 \%$ \\
Aporte Térmico (H) & $608,37 \mathrm{~J} / \mathrm{mm}$ & $867,47 \mathrm{~J} / \mathrm{mm}$ \\
Gás de proteção & $\mathrm{CO}_{2}$ & Argônio Puro \\
\hline
\end{tabular}


As energias de soldagem inseridas neste trabalho estão numa faixa de média energia de soldagem, tendo como referência valores de energias comumente utilizados nas indústrias em geral. As amostras apresentadas foram realizadas de acordo com o padrão da Thermon Indústria Mecânica, uma das colaboradoras deste projeto. Não houve tratamentos de pré ou pós soldagem.

Para avaliação comparativa dos processos TIG e FCAW foram realizados ensaios metalográficos de análise microestrutural da ZTA e metal base, considerando a influência da energia de soldagem.

As amostras soldadasforam cortadas, embutidas, lixadas por lixas de granulometria $100,220,320,400,600$ e 1200 mesh, ao final de cada etapa de lixamento as amostras foram devidamente lavadas e secadas. Após, as amostras foram polidas com pano de polimento adequado e pasta de alumina de 3, 0,3 e 0,05 microns.

$\mathrm{O}$ ataque químico foi realizado com a solução Behara modificada, composta por 100 $\mathrm{ml}$ de água, $200 \mathrm{ml}$ de ácido clorídrico (solução em estoque) e a cada $100 \mathrm{ml}$ de solução em estoque 0,5 a $1,0 \mathrm{~g}$ de metabissulfito de potássio.

Todas as imagens metalográficas, cálculos das frações volumétricas presentes e largura da ZAC deste estudo foram realizados no centro de pesquisa da Aperam South América emTimóteo.

O perfil de dureza HV foi realizado com o intuído de avaliar a mudança desta propriedade nos dois processos de soldagem comparados neste estudo.A impressão foi realizada pontualmente nas fases ferrita, austenita e interface ferrita/austenita partindo do metal de base para a zona fundida, com carga de $100 \mathrm{~g}$.

\section{RESULTADOS E DISCUSSÃO}

\subsection{Metal de Base}

A microestrutura, mostrada pela Figura 1, apresenta grãos de formato alongado na direção principal de conformação do metal de base. As soldas foram realizadas na direção perpendicular ao sentido de laminação da amostra. As fases presentes são a austenita (fase clara) e a ferrita (fase escura). A fração de ferrita foi de $50,13 \%$ e nenhuma fase indesejável foi observada. Imagem única, com ampliação de 200x, realizada com o auxílio do software Quantikov. 


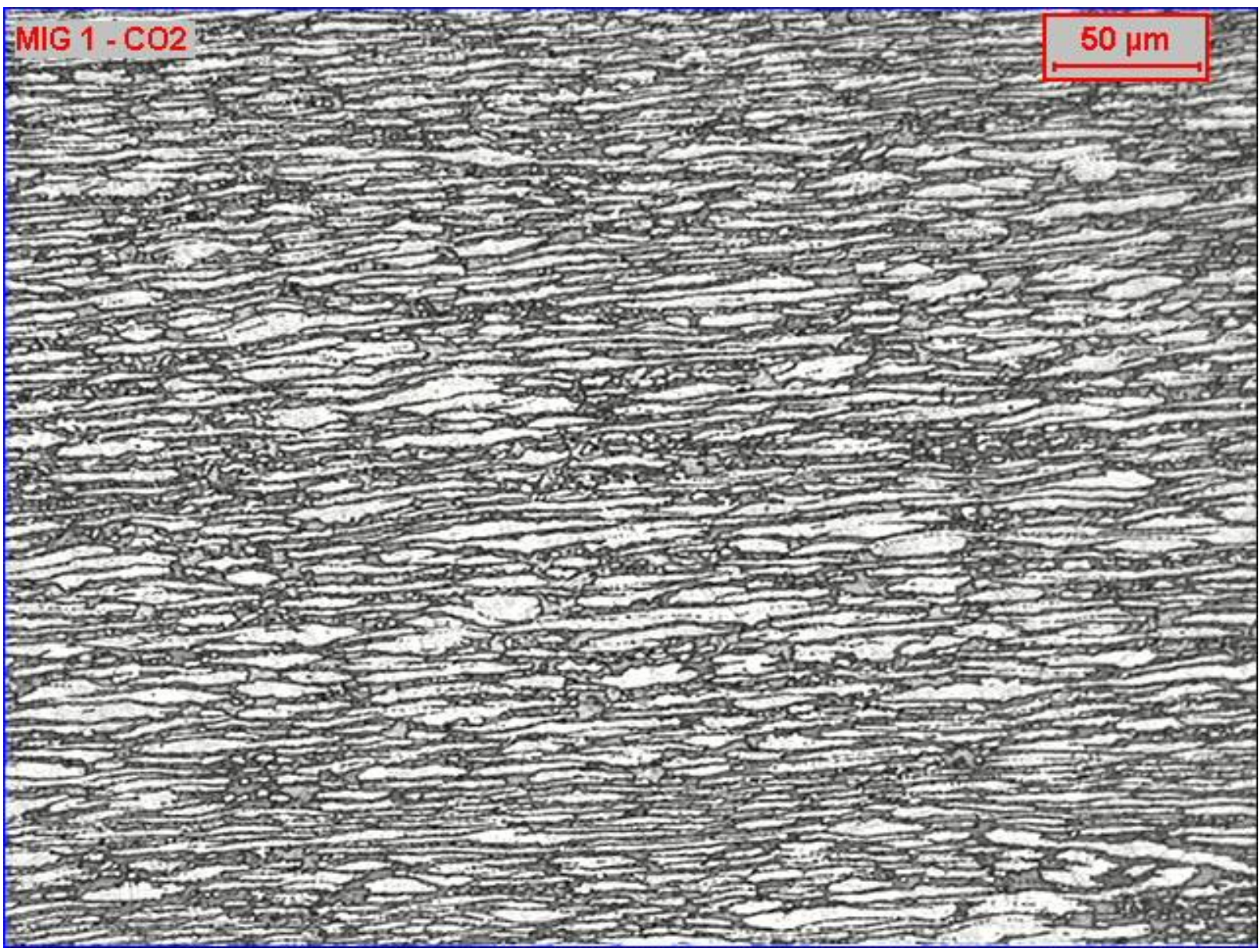

Figura 1. Distribuição de fases do metal de base AID, onde a fase atacada escura representa a fase ferrítica, e a fase atacada clara representa a fase austenítica. Imagem com ampliação de $200 \mathrm{X}$.

\subsection{Microdureza}

A diferença nas percentagens relativa de ferrita e austenita em cada energia de soldagem, realizadas por dois processos distintos, não interfere nos resultados da microdureza do material. Os resultados obtidos através da microdureza em cada junta soldada são apresentados na Tabela 4.

Tabela 4. Resultado de microdureza das regiões MB, ZTA e ZF

$$
\text { TIG }
$$

\section{FCAW}

\begin{tabular}{ccccccc}
\hline $\begin{array}{c}\text { Região } \\
\text { da Solda }\end{array}$ & $\begin{array}{c}\text { Média } \\
\text { HV }\end{array}$ & Média RC & $\begin{array}{c}\text { Erro } \\
\text { padrão } \\
(\%)\end{array}$ & $\begin{array}{c}\text { Média } \\
\text { HV }\end{array}$ & $\begin{array}{c}\text { Média } \\
\text { RC }\end{array}$ & $\begin{array}{c}\text { Erro } \\
\text { padrão } \\
(\%)\end{array}$ \\
MB & 295,03 & 29 & 1,4 & 277,73 & 26 & 0 \\
ZTA & 301,74 & 29 & 0 & 281,86 & 27 & 2,1 \\
ZF & 240,95 & 20 & 5,7 & 236,92 & 20 & 4,95 \\
\hline
\end{tabular}

\subsection{Processo TIG}

\subsubsection{Zona Termicamente Afetada}

Durante a solidificação da poça de fusão, uma estrutura colunar grosseira de ferrita é formada e à medida que o resfriamento ocorre, a precipitação da austenita e demais fases acontece. A austenita pode solidificar-se em três formas distintas a partir da ferrita. 
A primeira a se formar é a austenita alotromórfica de contorno de grão, de morfologia descontínua e se torna cada vez mais contínua à medida que a velocidade de resfriamento diminui. A segunda é a austenita Widmanstatten, nucleia-se a partir da primeira e cresce para o interior da mesma à medida que esta se torna saturada. A última a se formar é a austenita intragrunular, relação direta com a velocidade de resfriamento, ocorre na ausência de sítios para a nucleação e crescimento da austenita a partir da austenita de contorno de grão [8].

A precipitação da austenita na região da ZTA é influenciada, entre outras variáveis, pela composição química e velocidade de resfriamento. A Figura2 mostra a extensão média da ZTA, em torno de $240 \mu \mathrm{m}$.
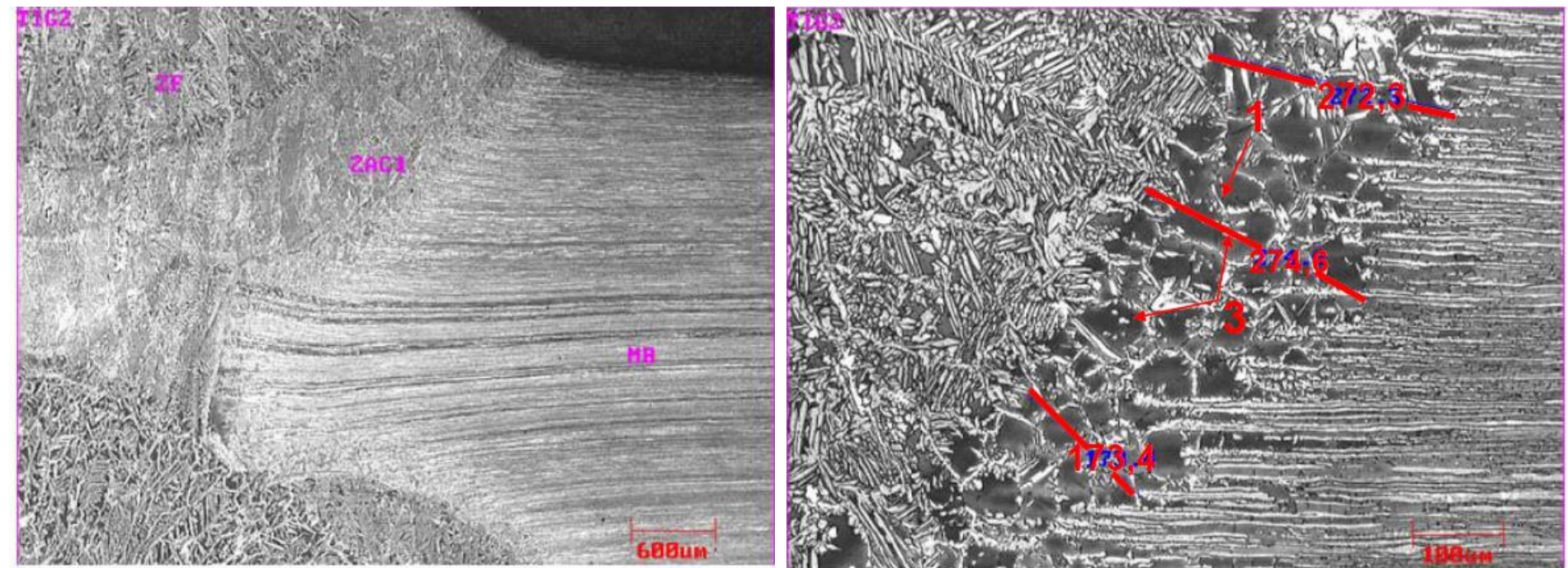

Figura 2. Extensão da ZTA direita superior. Superior 16X, inferior 100X.

Na ZTA observou-se a ocorrência dos três tipos de formação de austenita, porém a que mais se destacaram foram a alotromórfica de contorno de grão (1) e intragranular descontínua (3), devido os grãos ferríticos menores. A fração média observada, da região da ZTA, de fases austenita /ferrita é mostrada pela Tabela 5.

Tabela 5.Fração média austenita/ferrita na região da ZTA

\begin{tabular}{ccc}
\hline$\#$ & AUS(\%) & FER(\%) \\
\hline Average & 28.959 & 71.041 \\
StdDev & 5.4390 & 5.4390 \\
Minimum & 22.516 & 63.107 \\
Maximum & 36.893 & 77.484 \\
Count & 5.0000 & 5.0000 \\
\hline
\end{tabular}

\subsection{Processo FCAW}

\subsubsection{Zona Termicamente Afetada}

A Figura 3 mostra a extensão média da ZTA da região esquerda inferior, $472 \mu \mathrm{m}$. A figura apresenta também os tipos de formação de austenita, onde se destaca a intragranular descontínua (3), com ocorrência de grãos ferríticos maiores. A fração média observada, da região da ZTA, de fases austenita / ferrita é mostrada pela Tabela 6. 
Tabela 6. Fração média austenita/ferrita, região da ZTA

\begin{tabular}{ccc}
\hline$\#$ & AUS(\%) & FER(\%) \\
\hline Average & 29.406 & 70.594 \\
StdDev & 4.5374 & 4.5374 \\
Minimum & 26.139 & 62.074 \\
Maximum & 37.926 & 73.861 \\
Count & 5.000 & 5.000 \\
\hline
\end{tabular}
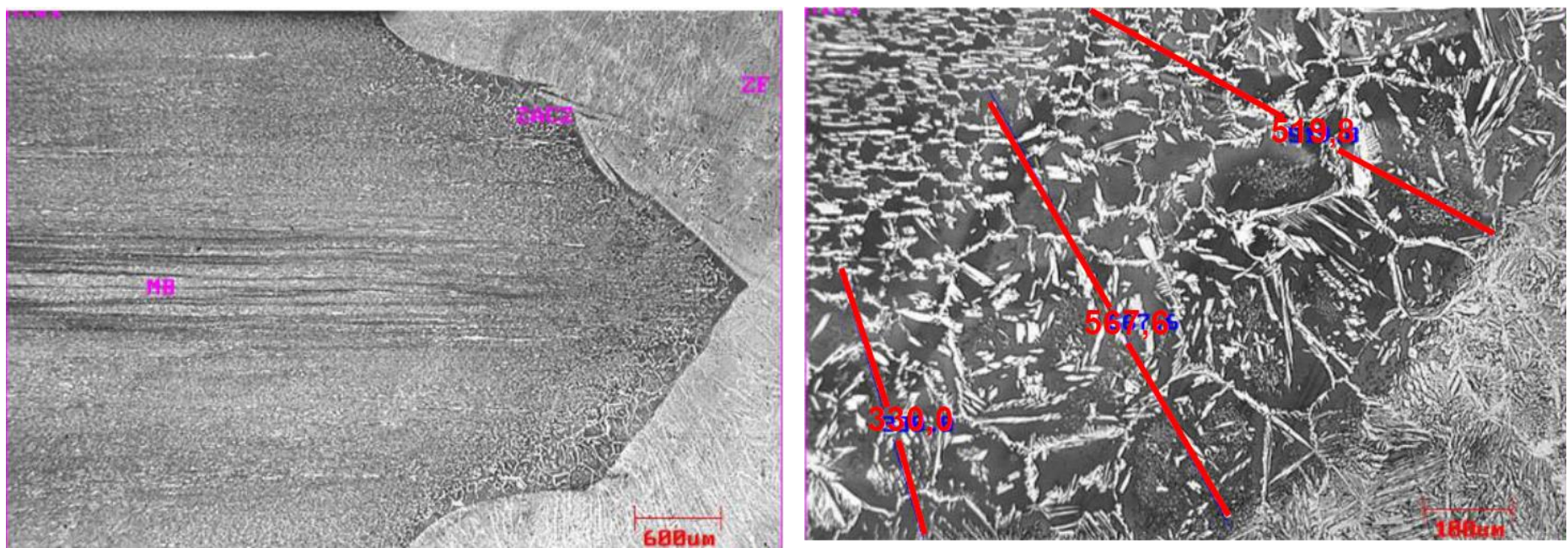

Figura 3: Extensão da ZTA esquerda inferior. Superior 16X, inferior 100X.

Quando comparamos a ZTA dosCPs obtido pelos dois processos, claramente observa-se, que a extensão da ZTA é muito maior pelo processo FCAW, justificado fortemente por apresentar maior velocidade de deslocamento e menor aporte térmico quando comparado com o processo TIG. Com isso, uma maior extensão da ZTA torna uma maior área suscetível a falhas e defeitos.

Ao comparar as frações de ferrita e austenitana ZTA, não houve tantas variações, $30 \%$ de austenita, aproximadamente nos dois casos, fato explicado pela baixa energia de soldagem que propiciou a ferritização acentuada da região, devido à alta velocidade de resfriamento, havendo pouco tempo para a formação da austenita secundária.

As diferenças de morfologias e distribuições de austenitareprecipitada na região da ZTA estão relacionadas com a quantidade de austenita dissolvida anteriormente e com a pequena diferença de energia de soldagem entre os $\mathrm{CPs}_{\text {; }}$, sendo assim, constatou-se que na amostra com soldagem TIG, houve maior presença de austenitaalotromórfica de contorno de grão, o que é explicado pela influência da baixa energia de soldagem, com grãos de ferrita menores. Já na amostra de soldagem FCAW, houve maior presença da austenitaintragranular, o que é explicado pela ocorrência de grãos ferríticos maiores.

\section{CONCLUSÃO}

Conclui-se que, quanto mais concentrada for a fonte de calor, menor será a extensão da região aquecida e, consequentemente, menores serão as mudanças nas propriedades da junta. Como também uma alta energia de soldagem, provoca uma baixa velocidade de resfriamento, o que permite a correta precipitação da austenita, mantendo o equilíbrio microestrutural. 
Verificou-se que o corpo de prova soldado pelo processo TIG apresentou menor região propensa a fragilizações, ou seja, menor ZTA do que a amostra soldada pelo processo FCAW nas condições testadas. E observou-se que as frações de austenita e ferrita em cada corpo de prova foram similares nesta região.

Conclui-se que a comparação entre os dois processos distintos resultou em fatos similares a outras bibliografias.

\section{Agradecimentos}

A Aperam South America, unidade de Timóteo em Minas Gerais.

A Thermon Indústria Mecânica de Timóteo em Minas Gerais.

A FAPEMIG e UNILESTE, pela bolsa e incentivo a pesquisa.

\section{REFERÊNCIAS}

1 PARDAL, J. M.;TAVARES, S. S. M.; PONZIO, E. A.; SCHMITT, V. M.Uma Revisão da Resistência à Corrosão em Aços Inoxidáveis Duplex e Superduplex.Rev. Virtual Quim.,2013, 5 (4), 658-677. Data de publicação na Web: 18 de agosto de 2013. Disponível em: <http://www.uff.br/rvq>. Acesso em: 01 de Dezembro de 2015.

2 ALVES NETO, Samuel Amora Alves Neto. Caracterização metalúrgica de juntas de aço inoxidável superduplex soldadas por processo TIG autógeno. 2011. 108f.Dissertação (Mestrado em Engenharia Mecânica) - Faculdade de Engenharia,Universidade do Estado do Rio de Janeiro, Rio de Janeiro, 2011.

3 MAGALHÃES, M. Formação de fase sigma em aço inoxidável dúplex SAF 2205 -

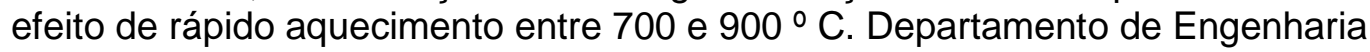
Mecânica - FEl, 2004.

4 SILVA, V.G Avaliação da susceptibilidade à corrosão sob tensão do aço inoxidável superduplex uns s32750 soldado pelo processo tig orbital em meios contendo cl-, $\mathrm{co} 2 \mathrm{e}$ h2s. 2012. 94f. Dissertação (Mestrado em Engenharia Mecânica) - Universidade Federal Fluminense. Niterói, 2012.

5 MARTINS, M.; CASTELETTI, L. C. Microstructural characteristics and corrosion behavior of a super duplex stainless steel casting. Materiais Characterization, v. 60, p. 150-155, 2009. Apud VELERIANO, L. C. Influência da Precipitação de Fases Secundárias na Resistência à Corrosão do Aço Inoxidável Super Duplex UNS S32520,2012, p.5. Programa de Pós - Graduação em materiais para engenharia Universidade Federal de Itajubá, março de 2012.

6 LIMA.B,C.; Efeitos da energia de soldagem na microestrutura do aço inoxidável superduplex UNS S32750. Universidade federal do Paraná, 1991.

7 ESAB. Centro de conhecimentos ESAB. Processos de soldagem: Arames Tubulares. Disponível em: <http://www.esab.com.br/br/pt/education/blog/processo_soldagem_arames_tubulares.c fm>.Acesso em: 04 de Abril de 2016.

8 PEREIRA, Patrícia Apicielo de Sousa. Efeito da energia de soldagem na microestrutura de um aço duplex e superduplex. Centro de Ciências e Tecnologia - CCT.

Universidade Estadual do Norte Fluminense Darcy Ribeiro - UENF, julho de 2009, p 9 - 22. (Dissertação de Mestrado em Engenharia e Ciências dos Materiais). Adaptado de: <http://uenf.br/posgraduacao/engenharia-de-materiais/wp-

content/uploads/sites/2/2013/07/Mestrado.pdf>. Acesso em: 01 de Dezembro de 2015. 